\title{
Influence of natural polysaccharides on the redox processes of CuTsPc thin films and dopamine sensing
}

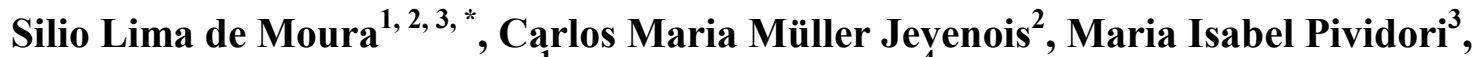 \\ José Aroldo Viana dos Santos ${ }^{1}$, Valtencir Zucolotto ${ }^{4}$, Ionara Nayana Gomes Passos ${ }^{1}$, \\ José Ribeiro dos Santos Júnior ${ }^{1}$
}

\author{
${ }^{1}$ Bioelectrochemistry Laboratory, Federal University of Piauí, Teresina 64049 550, Brazil \\ ${ }^{2}$ Electrodeposition and Corrosion Laboratory, University of Barcelona, Barcelona 08 028, Spain \\ ${ }^{3}$ Sensors and Biosensors Group, Autonomous University of Barcelona, Bellaterra 08 193, Spain \\ ${ }^{4}$ Nanomedicine and Nanotoxicology Laboratory, University of São Paulo, São Carlos 13560 970, Brazil
}

\section{Email address:}

siliosilicio@hotmail.com (S. L. de Moura)

\section{To cite this article:}

Silio Lima de Moura, Carlos Maria Müller Jevenois, Maria Isabel Pividori, José Aroldo Viana dos Santos, Valtencir Zucolotto, Ionara Nayana Gomes Passos, José Ribeiro dos Santos Júnior. Influence of Natural Polysaccharides on the Redox Processes of CuTsPc Thin Films and Dopamine Sensing. International Journal of Materials Science and Applications. Vol. 2, No. 5, 2013, pp. 146-156. doi: $10.11648 /$ j.ijmsa.20130205.11

\begin{abstract}
Energy diagrams have been obtained for copper tetrasulfonated phthalocyanine (CuTsPc) from electrochemical and electronic absorption measurements in layer-by-layer (LbL) films with cashew (Anacardium occidentale L.) and angico branco (Anadenanthera colubrina) natural polysaccharides in the anionic layers. In this study, LbL films were produced with either copper tetrasulfonated phthalocyanine or polysaccharides (cashew or angico branco). Since CuTsPc and the gums are polyanions, the multilayer deposition was carried out in a tetralayer fashion, in which a conventional cationic polyelectrolyte, namely poly (allylamine hydrochloride) (PAH), was interposed between the polyanionic layers. An alternative for the simultaneous determination of electrochemical signals was using the deconvolution procedure. Mathematical deconvolution of the peaks followed Gaussian analysis. The presence of the gum led to increased adsorption of the phthalocyanine, and enhanced the UV-VIS absorption and electrochemical response of the films. Furthermore, modified electrodes based on polysaccharides/phthalocyanine films were able to detect dopamine at concentrations as low as $10^{-5} \mathrm{~mol} / \mathrm{L}$.
\end{abstract}

Keywords: Natural Polymers, Copper Phthalocyanine, LbL Films, Mathematical Deconvolution, Dopamine

\section{Introduction}

Phthalocyanines have technological applications as photoresponsive materials in microelectronics, gas sensing, and modified electrodes for catalysis [1-3], due to their properties such as semiconductivity, well-defined redox activity and high thermal stability [3]. Metallic phthalocyanines and their derivatives, in particular, are interesting for electrochemistry, as well as for nonlinear optics, optical memories, sensors for toxic gases, organic solar cells and secondary batteries [1-5].

The polysaccharide extracted from cashew (Anacardium occidentale L.) [6-9] is a natural gum whose main function is to protect the tree against infections and/or wounds. These natural polysaccharides (NPS) are classified as hydrocolloids, with applications in cosmetics and the food industry, mainly as emulsification agents [10-14]. The angico branco (Anadenanthera colubrina) gum belongs to the family of legumes, and is composed of $20 \%$ galactose, $6 \%$ rhamnose and $10 \%$ glucuronic acid $[15,16]$. The cashew gum, this in turn has a lower percentage of glucuronic acid in its composition $(5 \%)$, which causes the character acid and anionic in both gums. It is found in several regions of Brazil, including the states of Piauí, Bahia, Minas Gerais, Goiás and Amazonas. The polyanionic character of angico gum arises from the presence of carboxylic acid groups, through which intermolecular interactions may occur $[6,7,15]$. Technological interest in cashew and angico branco gums, which has been proven to be compatible with many synthetic polymers, comes mainly from their biodegradability and mechanical properties.

The incorporation of modified phthalocyanines into a polymeric matrix is an efficient strategy for obtaining electroactive nanocomposites with distinct and optimized 
properties [3,17]. Recent studies have shown that sulfonated metallophthalocyanines can be assembled together with conventional polyelectrolytes or conducting polymers, using the layer-by-layer technique (LbL), for sensing and electronic applications [20,23]. The main advantage in processing phthalocyanines in the form of nanostructured layered composites is that film thickness and architecture can be controlled at the molecular level [22].

Given the above, it should be noted that there is currently no study in the literature investigating charge densities in LbL films produced with copper tetrasulfonated phthalocyanine (CuTsPc)/NPS, since the intermediate oxidation/reduction LbL films of this type are usually found in potential mixed together. This factor makes it impossible to quantify individual intermediaries, requiring the detection of the electrochemical signal of each without interferences from the other signals. This can be achieved by deconvolution of electrochemical signals, a technique used in spectroscopy when there is an overlap in the absorption bands [24, 25].

In phthalocyanine-containing LbL films, parameters such as ionization potential (IP), electroanity (EA) and energy gap (Eg) are important to understand and control the electrical, optical and chemical properties of the films [3]. Such parameters may be used to obtain energy level diagrams [26-29].

In this study, LbL films were produced based on the alternate adsorption of $\mathrm{CuTsPc}$, and cashew or angico branco natural gums. Since CuTsPc and NPS are polyanions, the multilayer deposition was carried out in a tetralayer fashion in which a conventional cationic polyelectrolyte, namely poly (allylamine hydrochloride) (PAH), was interposed between the polyanionic layers. The influence of the gums on the (PAH/NPS/PAH/CuTsPc) nanocomposites (where $n$ is the number of tetralayers) was investigated through spectroscopy and electrochemical experiments. The optical and electrochemical parameters were employed to estimate the Eg and IP of the LbL films, from which the energy level diagrams were developed. We also investigated the ability of the nanocomposites to act as modified electrodes for dopamine sensing.

\section{Experimental}

Cashew and Angico Branco gums were extracted in Água Branca City in Piauí State (Northeast region of Brazil) in September 2012, and purified in the form of sodium salt as described elsewhere [32]. After purification, $0.25 \mathrm{~mL}$ of ethanol was added to $5.0 \mathrm{~g}$ of gum, which was immediately dissolved in $100 \mathrm{~mL}$ of Milli-Q water under stirring for $24 \mathrm{~h}$, followed by filtration. The final aqueous solution had a concentration of $50 \mathrm{mg} / \mathrm{mL}$ and $\mathrm{pH} 6.5$, as the $\mathrm{pKa}$ of glucuronic acid is 2.93 [33], the $\mathrm{pH}$ was adjusted with $0.1 \mathrm{M}$ $\mathrm{HCl}$. All the reagents were purchased from VETEC (Brazil) and were of analytical grade. CuTsPc and PAH were purchased from Aldrich Co. and used without further purification in aqueous solutions at a concentration of 0.5 $\mathrm{mg} / \mathrm{mL}$ and $\mathrm{pH}$ 5.0. The chemical structures of the materials employed are depicted in Fig. 1.

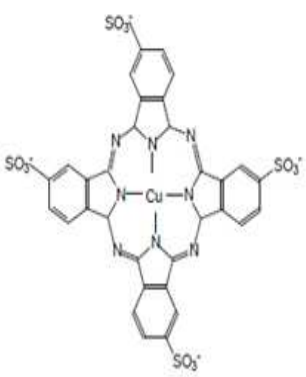

(a)

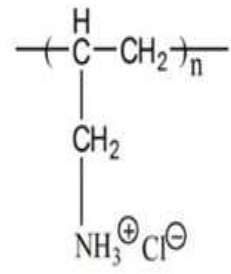

(b)

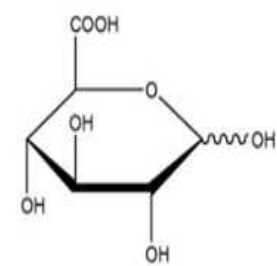

(c)
Figure1. Chemical structures of (a) CuTsPc, (b) poly(allylamine hydrochloride) (PAH) and (c) glucuronic acid.

Natural gum-containing films were adsorbed onto glass and glass covered with indium tin oxide (ITO) substrates in a tetralayer fashion. Two distinct architectures were investigated: (PAH/NPS/PAH/CuTsPc) ${ }_{n}$ (sequence 1) and (PAH/CuTsPc/PAH/NPS) ${ }_{n}$, (sequence 2 ), where $n$ was the number of tetralayers. Multilayer films with $n$ ranging from 1 to 10 were obtained by immersing the substrate in the polycationic solution (PAH) and then in the anionic ( $\mathrm{CuTsPc}$ or NPS) solution (according to the architecture desired) for 1 min (Fig. 2). After deposition, the substrates were rinsed with distilled water and dried under a nitrogen flow.

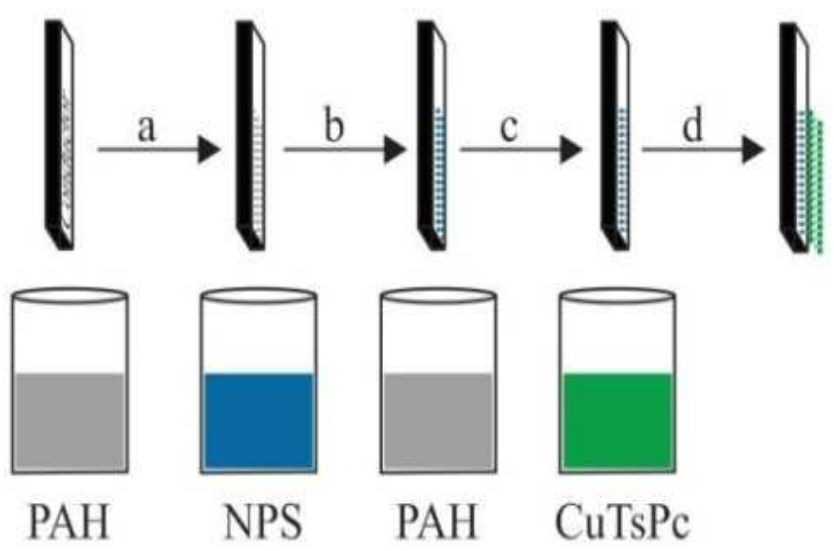

Figure2. Schematic representation of the manufacturing process, showing the self-assembly of nanostructured films (one tetralayer) using a cationic polyelectrolyte, PAH, and anionic CuTsPc or NPS.

UV-Vis spectroscopy was performed with the HITACHI U-3000 spectrophotometer. Spectra were obtained from aqueous solutions of $\mathrm{PAH}$, gums and dilute solutions containing copper phthalocyanines. The UV-Vis spectra from LbL films with (PAH/CuTsPc)n, (PAH/NPS)n, (PAH/NPS/PAH/CuTsPc) $n$ and (PAH/CuTsPc/PAH/NPS) $n$ were collected from the first to the tenth bi/tetralayers.

Cyclic voltammograms were collected with LbL films deposited onto ITO using a potentiostat Autolab PGSTAT30N and a $10 \mathrm{~mL}, 3$-electrode electrochemical cell. The reference electrode was $\mathrm{Hg} / \mathrm{HgCl} / \mathrm{KCl}_{\text {(sat.) }}(\mathrm{SCE})$; a 1.0 $\mathrm{cm}^{2}$ platinum foil was used as an auxiliary electrode. The 
LbL films deposited in the sequences (1) and (2) on ITO with an active area of $0.4 \mathrm{~cm}^{2}$ (geometric area) were employed as working electrodes. Experiments were carried out using a solution of $\mathrm{H}_{2} \mathrm{SO}_{4}(0.05 \mathrm{~mol} / \mathrm{L})$ at $22{ }^{\circ} \mathrm{C}$ (Under the conditions used for $\mathrm{pH}$, temperature and time, this electrolyte is not able to force an acid hydrolysis of polysaccharides into soluble sugars, this gums are stable in these conditions [33]). Also the experiments were carried under an oxygen atmosphere, there is not effect of the oxygen on voltammetric response of the modified electrode $\left(\mathrm{E}_{\text {(oxigen) }}^{\mathrm{o}}=1.229 \mathrm{~V}\right)$ [34]. For comparison, cyclic voltammograms were obtained using $\mathrm{LbL}$ films with the

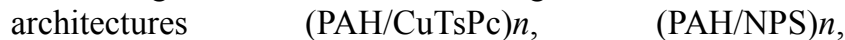
(PAH/NPS/PAH/CuTsPc) $n$ and (PAH/CuTsPc/PAH/NPS) $n$ as working electrodes, where $n$ was the number of bi/tetralayers. Cyclic voltammetry was also employed for detecting dopamine (DA), with DA being added in the electrolytic solution in a concentration range from 25 to $90 x$ $10^{-6} \mathrm{~mol} / \mathrm{L}$.

The energy diagram described the magnitude of the energies involved in the highest (HOMO) and lowest unoccupied molecular orbital (LUMO) of the nanocomposites in the form of the LbL films, serving as an important guide for predicting optical, magnetic, electrical and electrochemical properties [26,35].

The procedure described by Micaroni et al. (2002) used experimental data such as UV-VIS electronic spectra and cyclic voltammograms for constructing energy diagrams by calculating electroaffinity (EA), ionization potential (IP) and the energy gap $(\mathrm{Eg})$. However, it is essential that the criteria for stability and reversibility of the electrode are met, so that the energies involved in charge transfer of the film can be calculated.

For films constructed with copper phthalocyanine and natural polysaccharide, mathematical deconvolution was used to separate the peaks because of overlapping. For deconvolution analysis, all of the curves generated by the summing of deconvolution were generated according to the Gaussian equation [36].

$$
\mathrm{y}=\mathrm{y}_{0}+\operatorname{Aexp}-\left(\mathrm{x}-\mathrm{x}_{\mathrm{c}}\right)^{2} / \mathrm{w}^{2}
$$

\section{Results and Discussion}

\subsection{Spectroscopy Analysis}

The absorption spectra of self-assembled films containing copper phthalocyanine and the natural polysaccharides of cashew and angico branco are illustrated in Fig. 3, where the growth of the film with the number of bi/tetralayers can be observed. There was an intense absorption band at $615.5 \mathrm{~nm}$ corresponding to dimeric species (or aggregates) and a small shoulder at $680 \mathrm{~nm}$ that may be related to the presence of monomeric species of tetrasulfonated phthalocyanine[3].

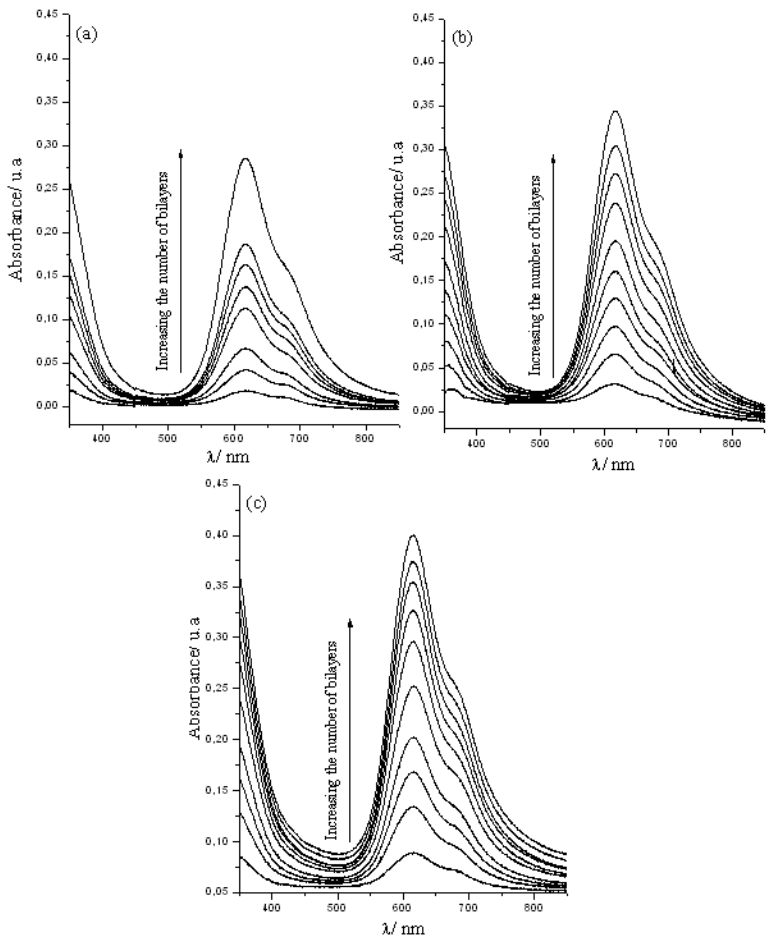

Figure3. Absorption spectra for films formed in sequence 1: (a) $\mathrm{PAH} / \mathrm{Cu} \mathrm{TSPC}_{\mathrm{P}}$ (b) PAH/Cashew/PAH/CuTSPc and (c) PAH/Angico/PAH/CuTsPc.

For copper phthalocyanine in solution, the Q-band absorption is affected by aggregation of the substituent groups, which may lead to a shift and broadening of the absorption band [3]. Such shifts are possibly related to molecular interactions between molecules of copper phthalocyanine and natural polysaccharides. The latter can interfere with the conformation of the molecules and lead to aggregate formation.

When molecules are aligned parallel to the substrate surface, growth is associated with a higher amount of adsorbed phthalocyanine due to face-to-face conformations adopted by them, as reported previously $[20,22]$.

The films investigated were obtained with the sequence (PAH/CuTsPc/PAH/NPS). We observed the same characteristics of maximum absorption peaks in sequence 1 , but with less intense absorption bands. Fig. 4 illustrates the comparison between the tenth bi/tetralayer films containing copper phthalocyanine and those with natural polysaccharides in both sequences 1 and 2 .

From Fig. 4, it can be inferred that there was a linear relationship between the absorbance values obtained from the peak $(615 \mathrm{~nm})$ and the number of bi/tetralayers deposited on the substrate. This indicates that deposition is a self-regulated process resulting in the same amount of material being adsorbed at each step. 

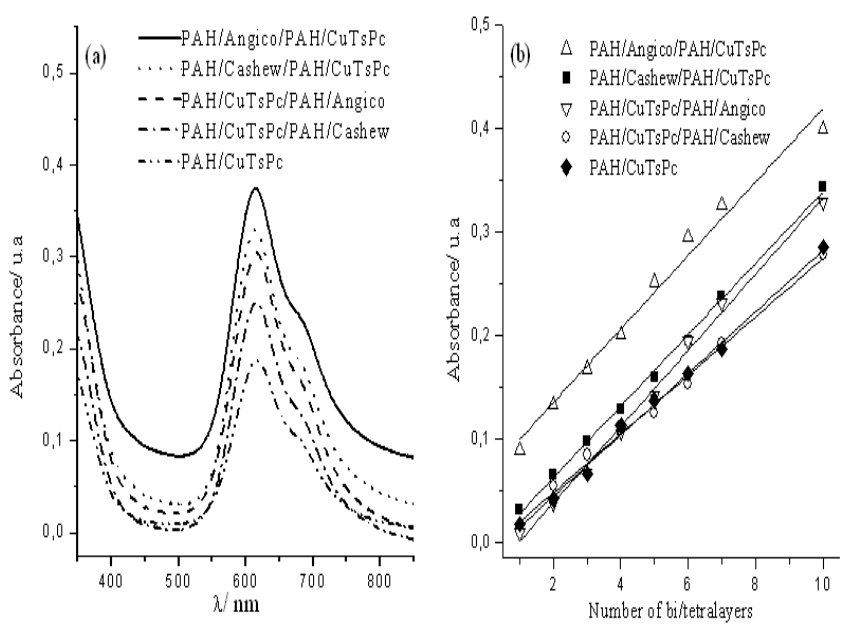

Figure4.(a) UV-VIS spectra comparing the tenth bi/tetralayers and (b) linear relationship of maximum absorbance $(615 \mathrm{~nm})$ versus the number of bi/tetralayers of self-assembled films produced with CuTsPc or cashew or angico branco polysaccharide.

A comparison between sequences 1 and 2 indicated that the best adsorption conditions occurred for films containing angico branco and built according to sequence 1, demonstrating the ability of this gum to form self-assembled films. This can be attributed to large amounts of glucuronic acid, which is twice as high than the cashew polysaccharide, ie, incorporation of molecules of copper phthalocyanine relative to the cashew polysaccharide in the initial stage of deposition. This was also proven by the electrochemical measurements.

\subsection{Electrochemical Characterization}

The supporting electrolyte used for electrochemical measurements was $0.05 \mathrm{~mol} / \mathrm{L}$ of $\mathrm{H}_{2} \mathrm{SO}_{4}$. The monovalent ion $\mathrm{HSO}_{4}^{-}$displays its charge near the surface, thus increasing the electric field and the force of attraction exerted on the water molecules. Furthermore, the lower mobility of $\mathrm{HSO}_{4}^{-}$causes steric hindrance of the active structure of the film, showing well-defined redox processes [37]. The amount of adsorbed material and the porous structure of the films affect the electrochemical activity of chemically modified electrodes. The electrochemical reaction has electroactive sites accessible from the supporting electrolyte through its permeability within the pores of the structure. Thus, with an increasing number of layers deposited on the substrate, a growing number of sites become available to the redox reactions and therefore, lead to a greater current response being displayed by the system.

The films containing only the PAH and the cashew or angico branco gum on the ITO substrate surface exhibited no electrochemical activity (Fig. 5). The presence of the gum in the tetralayers was confirmed by the increased level of current to the two redox processes, when compared to the film containing the $\mathrm{PAH} / \mathrm{CuTsPc}$ bilayers. The exception was the film containing angico branco, which apparently displaced the first redox process to the metal center, as seen in Fig. 6.

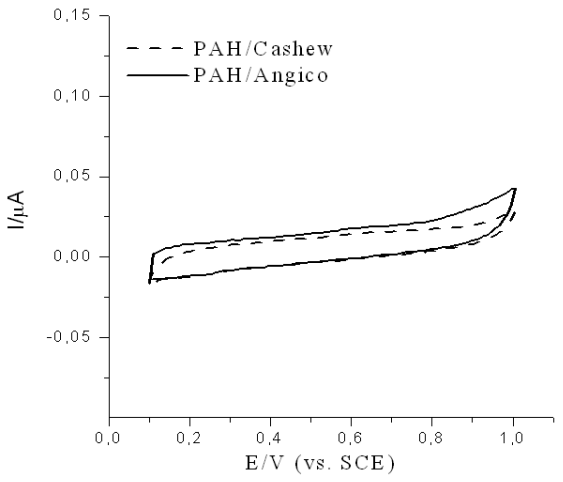

Figure5. Cyclic voltammograms for the PAH/Cashew and PAH/Angico films (5 bilayers), deposited on a substrate of pure ITO, in $\mathrm{H}_{2} \mathrm{SO}_{4}(0.05$ $\mathrm{mol} / \mathrm{L}$ ) at $50 \mathrm{mV} / \mathrm{s}$.

Cyclic voltammograms for the PAH/NPS/PAH/CuTsPc films containing 3, 5, 7 and 10 tetralayers revealed the correlation between the charge transfer mechanism and the number of bi/tetralayers. Comparing the electrochemical activities between films, the system mounted with the sequence PAH/CuTsPc/PAH/NPS (sequence 2) did not show better results.

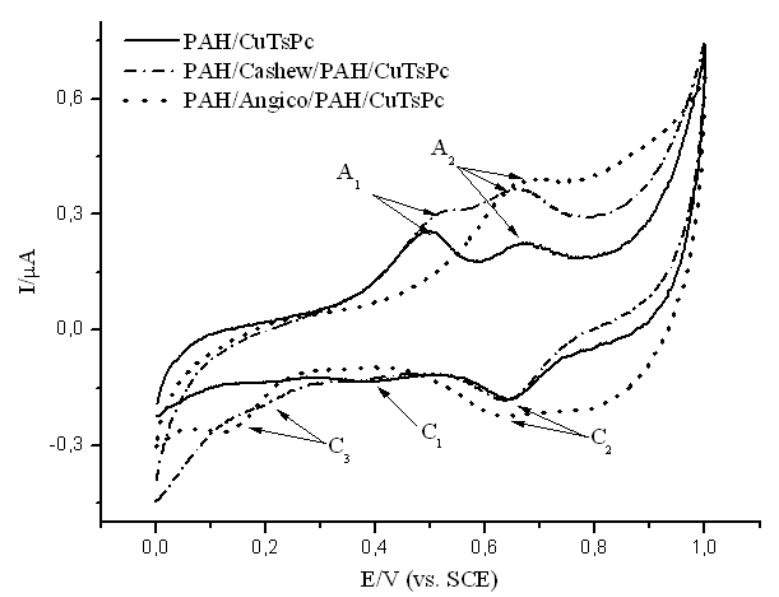

Figure6. Comparison between the electrochemical activity of the films $\mathrm{PAH} / \mathrm{CuTSPc}$, PAH/Cashew/PAH/CuTsPc and PAH/Angico/PAH/CuTsPc containing 5 bi/tetralayers in $\mathrm{H}_{2} \mathrm{SO}_{4}(0.05 \mathrm{~mol} / \mathrm{L})$ at $50 \mathrm{mV} / \mathrm{s}$.

Our results revealed that the electrochemical film profile varied with the higher numbers of deposited bi/tetralayers and the larger current responses of the system. This was due to the high number of active sites available. The film with 3 tetralayers displayed two peaks of oxidation, corresponding the first to metal center and the second to macrocycle present in the phthalocyanine molecule; however, this film showed that the current response of the system was relatively lower than that of the film containing 5 tetralayers. The oxidation of the metal center was difficult for films with 7 and 10 tetralayers, this oxidation peak was much less defined in these films than in that with 5 tetralayers. This is due to the mobility of ions into and out of the film structure, as well as an increase in the amount of material adsorbed. The access of chemical species of the supporting electrolyte to active sites of the system is hampered, thereby impeding the 
transfer of charges and also causing overlapping peaks. The explanation about the current levels and peak shifts are explained in section 3.2.1.

When it comes to the number of layers, the film containing $5 \mathrm{bi} /$ tetralayers in the PAH/NPS/PAH/CuTsPc sequence (Fig. 6) presented better electrochemical responses than the other systems with cashew and angico branco gums. Moreover, showed higher levels current to peaks of oxidation and reduction, as proven by measurements of electronic UV-VIS absorption (Fig. 3).

Changes in electrochemical activity of the films at different scan speeds are an important tool for elucidating the mechanism governing the redox process of the material $[22,23]$.To perform this, voltammograms were recorded for films containing $5 \mathrm{bi} /$ tetralayers, varying the scan rate between 25 and $150 \mathrm{mV} / \mathrm{s}$ (Fig.7).

The linear relationship (Fig. 7b) between the anodic and cathodic peak current ( $i_{\mathrm{A} 2}$ and $i_{\mathrm{C} 2}$, respectively) and scan rate was obtained from the data of currents and velocities in Fig. 7a. The linear relation ship indicated that the electrochemical reaction was controlled by charge transfer through the redox centers and the neighboring ITO substrate surface. This charge transfer mechanism, called electron hopping, is the displacement of electronsby the porous structure of the film occurring under the influence of a chemical potential [36]. The electron transfer process is a consequence of immobilization of chemical species on the substrate [40].This process was observed in the studied films.
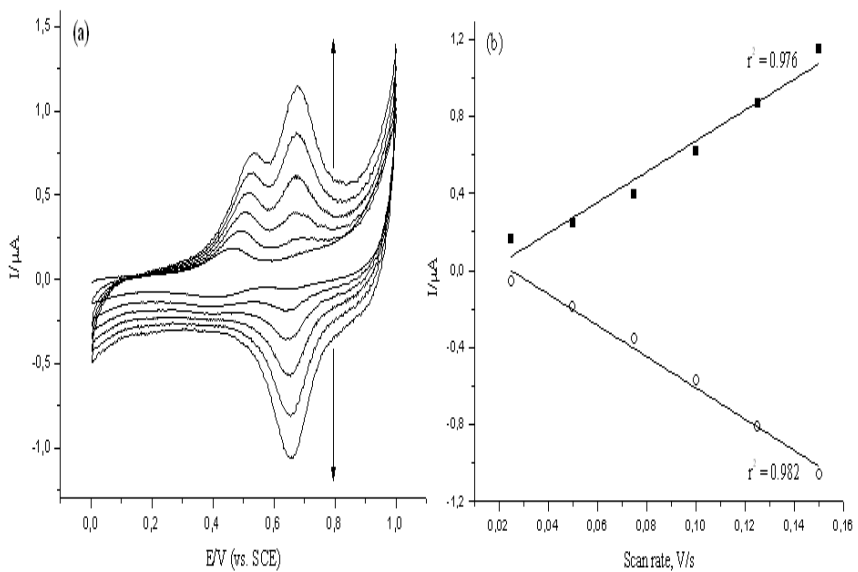

Figure7. (a) Cyclic voltammograms with different scan speeds for $L b L$ films produced with $\mathrm{PAH} / \mathrm{CuTs} \mathrm{Pc}$ in $\mathrm{H}_{2} \mathrm{SO}_{4}(0.05 \mathrm{~mol} / \mathrm{L})$ from 25 to 150 $\mathrm{mV} / \mathrm{s}$; (b) linear relationship between (-) $i_{A 2}$ and (O) $i_{C 2} v s$. scan speeds.

The stability test of the films consisted of applying a range of potentials $(0.0$ to $1.0 \mathrm{~V})$ for several successive cycles (Fig. 8). The initial current decreased, but this decrease was stabilized after several cycles. The electrochemical stability of the films in the electrolyte followed the order $\mathrm{PAH} / \mathrm{CuTsPc}>$ $\mathrm{PAH} /$ Cashew/PAH/CuTsPc $>\mathrm{PAH} /$ Angico/PAH/CuTsPc.
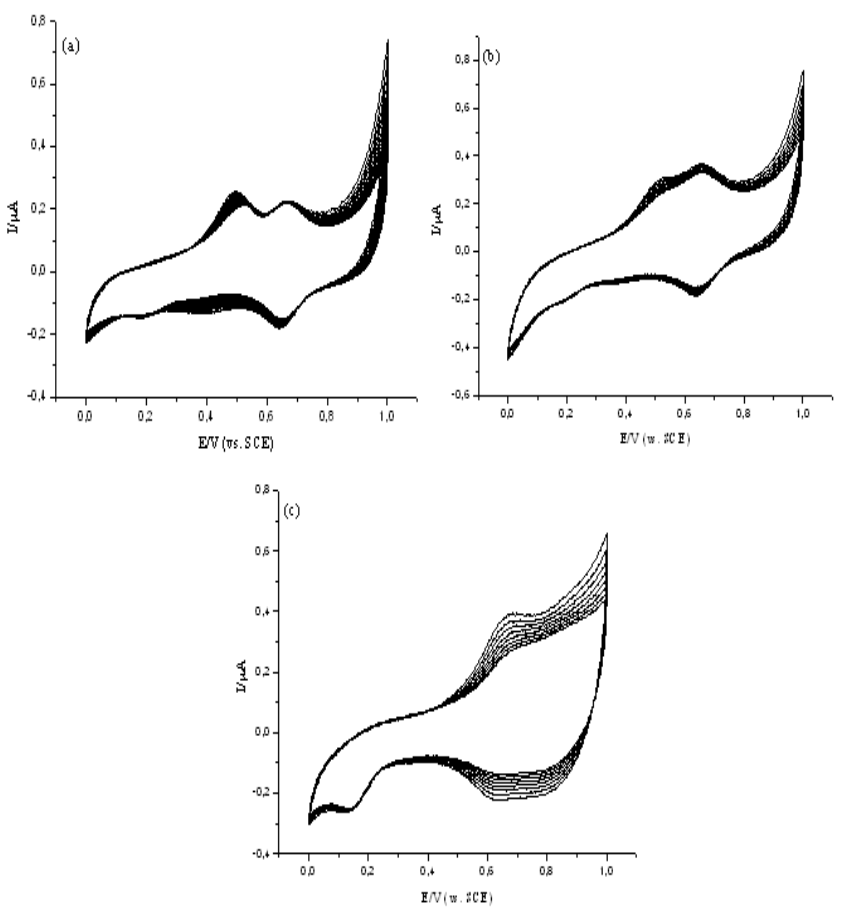

Figure8. Cyclic voltammograms containing 50 successive cycles in $\mathrm{H}_{2} \mathrm{SO}_{4}$ (0.05mol/L) at $50 \mathrm{mV} / \mathrm{s} \mathrm{for} \mathrm{LbL} \mathrm{films} \mathrm{with} 5$ bi/tetralayers: (a) PAH/CuTsPc, (b) PAH/Cashew/PAH/CuTsPc and (c) PAH/Angico/PAH/CuTsPc.

\subsubsection{Deconvolution of Electrochemical Signals}

Under conditions of large differences between the values of oxidation and reduction potentials of thin films, measurements were taken to study the possibility of simultaneously determining the electrochemical signals. Thus, CuTsPc/NPS films were evaluated by cyclic voltammetry. As expected, the results obtained did not show clearly the formation of separate peaks for films containing polysaccharides, particularly for angico branco. Instead, there was a formation of a single extended oxidation peak (Fig. 6), with the potential to peak at about $0.65 \mathrm{~V}$ (compared to SCE) and a peak reduction of about $0.80 \mathrm{~V}$ (compared to SCE). Hence, it was impossible to simultaneously determine these signals using only cyclic voltammetry.

Thus, an alternative for examining electrochemical signals is using the deconvolution procedure by employing the formula of Gaussian analysis (Eq. 1).

To perform the deconvolution of the peaks, the current generated by the electrical double layer of each film was first subtracted, serving as a baseline, i.e., the current generated by the PAH/gum films (see Fig. 5). After, the number that determined the expected peaks was selected. Following this step, the potential peak was fixed for the oxidation and/or reduction of each film, and Gaussian analysis was applied separately, resulting in the deconvolution of the peaks. Fig. 9 shows the voltammograms related to the sum of the peak currents deconvoluted for each film. 


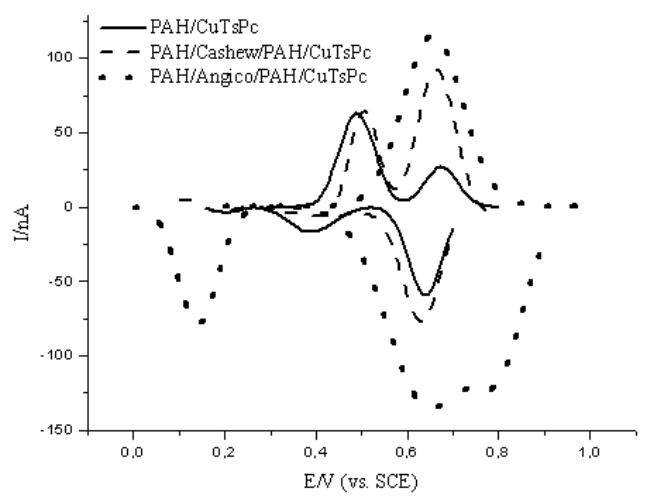

Figure9. Cyclic voltammograms related to the sum of the peak current deconvoluted for the films $P A H / C u T S P c, P A H / C a s h e w / P A H / C u T s P c$ and PAH/Angico/PAH/CuTsPc containing 5 bi/tetralayers in $\mathrm{H}_{2} \mathrm{SO}_{4}(0.05 \mathrm{~mol} / \mathrm{L})$ at $50 \mathrm{mV} / \mathrm{s}$.

For the PAH/CuTsPc film, two oxidation processes of the material were identified, the first on the metal center $\left[\mathrm{Cu}(\mathrm{I}) / \mathrm{Cu}(\mathrm{II})+e^{-}\right]$at $0.48 \mathrm{~V}$, with a corresponding reduction peak at $0.39 \mathrm{~V}$, and the second due to the phthalocyanine macrocycle $\left[\mathrm{FtTs}^{6-} / \mathrm{FtTs}^{4-}\right]$ at $0.67 \mathrm{~V}$, with a corresponding reduction peak at $0.64 \mathrm{~V}$, this be according with Leznoff and Lever [3].

Table 1 illustrates the potential of the anodic and cathodic peaks, and their respective numbers of charge densities, for films studied at the scan rate of $50 \mathrm{mV} / \mathrm{s}$.

The oxidation potential of the metal center $\left(\mathrm{A}_{1}\right)$ for the $\mathrm{PAH} / \mathrm{Cashew} / \mathrm{PAH} / \mathrm{CuTsPc}$ film shifted to more positive values when compared to that of the PAH/CuTsPc film. This suggests that the existence of electron donors in the cashew gum, the carboxyl groups, acted by reducing the charge on the phthalocyanine ring, thereby requiring more energy for the reaction to occur. Since the oxidation potential of the macrocyclic ring behaved quite differently at less positive values, this process occurred more in films containing cashew gum. The charge density of this redox process was approximately two times higher than that of the $\mathrm{PAH} / \mathrm{CuTsPc}$ film.

Table 1. The peak potential of the anodic and cathodic regions, and their respective charge densities, for films studied at a scan rate of $50 \mathrm{mV} / \mathrm{s}$.

\begin{tabular}{llll}
\hline & \multicolumn{2}{l}{ Charge density, $\left(\mathbf{n C} / \mathbf{c m}^{2}\right)$} & \\
\hline Potential & Anodic region & & PAH/Angico/PAH/CuTsPc \\
& PAH/CuTsPc & PAH/Cashew/PAH/CuTsPc & - \\
$\mathrm{A}_{1}(\approx 0.49 \mathrm{~V})$ & 10.228 & 11.781 & 20.662 \\
$\mathrm{~A}_{2}(\approx 0.67 \mathrm{~V})$ & 4.153 & 7.934 & \\
& Cathodic region & & PAH/Angico/PAH/CuTsPc \\
& PAH/CuTsPc & PAH/Cashew/PAH/CuTsPc & 28.591 \\
$\mathrm{C}_{1}(\approx 0.39 \mathrm{~V})$ & 1.991 & 3.488 & 13.319 \\
$\mathrm{C}_{2}(\approx 0.64 \mathrm{~V})$ & 5.317 & 8.494 & 8.388 \\
$\mathrm{C}_{3}(\approx 0.20 \mathrm{~V})$ & 0.251 & 0.515 & \\
\hline
\end{tabular}

These observations suggest that the interaction of cashew gum with other materials at the nanometer level occurs to promote the synergy between them, improving the of current responses of the redox processes.

In the specific case of the film with angico branco gum, there was only one anodic peak; however, the current response (Fig. 9) stood out for having a charge density almost five times as high for the second oxidation process $\left(\mathrm{A}_{2}\right)$ on the macrocyclic ring, when compared to the $\mathrm{PAH} / \mathrm{CuTsPc}$ film (Table 1). This was also proven by the UV-VIS measurements. Thus, we can infer that the oxidation and reduction of the metal center occur for more positive values, when compared to the $\mathrm{PAH} / \mathrm{CuTsPc}$ film. These overlap with the oxidation and reduction potentials of the macrocycle. However, when we apply the Gaussian deconvolution, the reduction peaks of the macrocycle and metal center separate, but this is not seen with the anodic peaks. This can be attributed to large amounts of glucuronic acid, which is twice as high than the cashew polysaccharide. This creates an overlap between the redox process of the CuTsPc metal center and that of the macrocycle, as already reported [41].
In these films, the highest rate of degradation was observed for the film containing the polysaccharide of angico branco $\left(+0.14 \mathrm{~V}\left(\mathrm{C}_{3}\right)\right)$ (Fig. 9). This process is intrinsic in $\mathrm{PAH} / \mathrm{CuTsPc}$ films because it occurs in the absence of polysaccharides. However, we observed that this process accelerated when a large amount of acid was incorporated into the electrode surface.

Fig. 10 shows the relationship between the anodic and cathodic charge densities $\left(\mathrm{Q}_{\mathrm{A}} / \mathrm{Q}_{\mathrm{C}}\right)$ of the redox processes of the metal center and macrocycle in the LbL films. There was a decrease in the charge density of the metallic center with an increase in the amount of glucuronic acid (Fig. 10a). This may be linked to the conformation of the phthalocyanine molecules when they stack in the face-to-face conformation in the self-assembling films. The presence of carboxylic acids in NPS hinders the transfer of charges in the process.

In Fig. 10a, the point related the charge density to NPS angico is a theoretical point that has been stipulated by the equation of the line $\left(\mathrm{Q}_{\mathrm{A}} / \mathrm{Q}_{\mathrm{C}}=5.134-0.294[\%\right.$ glucuronic acid]), as explained earlier, and with this process of deconvolution analysis was not possible to identify the anodic process the metal center, as shown in Fig. 9. The 
charge density of the macrocycle behaved quite differently, shifting to the highest values and suggesting that this process was easier in films containing NPS (Fig. 10b). A ratio of the sums of the densities of anodic charge of each process $\left(\mathrm{Q}_{\mathrm{A} 1}\right.$ $+\mathrm{Q}_{\mathrm{A} 2}$ ) for each film also explained the overlapping of the peaks. Angico branco gum was characterized by a single broad peak that was much higher in relation to those of the other films, suggesting that the $A_{1}$ peak overlapped with the $\mathrm{A}_{2}$ peak. This again confirmed the ratio of the anodic and cathodic charge densities. Fig. 9a shows that the redox activity of the metal center decreased with increasing amounts of glucuronic acid. This might be due to the difference in mass of the material adsorbed onto the ITO surface, which is different for each film, in accordance with the UV-VIS results (Fig. 4b).
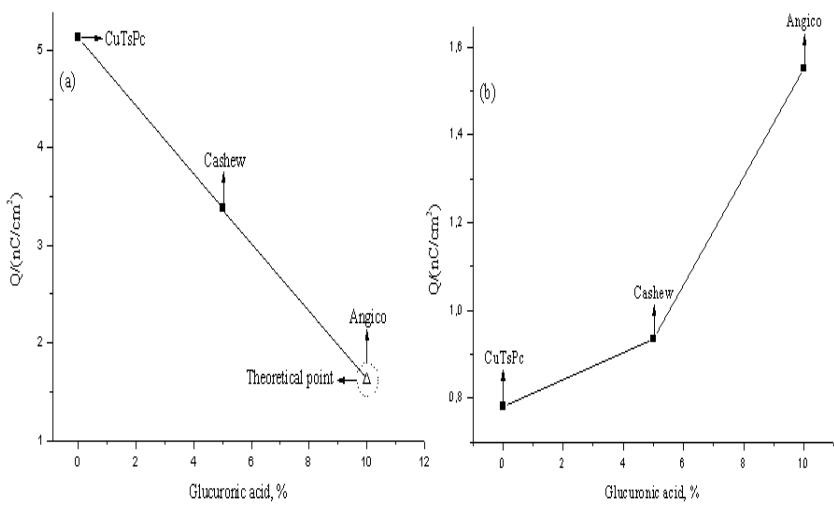

Figure10.Relation between anodic and cathodic charge densities for redox processes of the (a) metal center and (b) macrocycle as a function of the percentage of glucuronic acid.

It is important to point out that with the separation of the oxidation and reduction peaks of the films, the deconvolution peaks obtained had profiles and curve shapes with symmetrical Gaussian bell-shapes, yielding satisfactory results.

Table 2.Parameters for constructing energy diagrams and determining their forms.

\begin{tabular}{|c|c|c|}
\hline Parameters & Acronym/Unit & Way ofprocurement \\
\hline Initialpotentialofoxidation & $\mathrm{E}_{\mathrm{ox}}^{\prime} v s . \mathrm{ESC} / \mathrm{V}$ & $\begin{array}{l}\text { In the cyclic voltammogram, the intersection of the tangent to the growth of current and oxidation } \\
\text { current background }\end{array}$ \\
\hline Potentialofoxidation & $\mathrm{E}_{\mathrm{ox}} / \mathrm{V}$ & Calculation: $\mathrm{E}_{\mathrm{ox}}+\mathrm{E}_{\mathrm{vac}}+4.7\left(\mathrm{E}_{\mathrm{vac}}=0\right)$ \\
\hline Potentialionization & $\mathrm{PI} / e \mathrm{~V}$ & Calculation: $e \mathrm{E}_{\mathrm{ox}}(e$ being the electron charge) \\
\hline Wavelength & $\lambda^{\prime} / \mathrm{nm}$ & $\begin{array}{l}\text { In the electronic spectrum, the intersection of the tangent to the curve of maximum absorption and } \\
\text { absorption background }\end{array}$ \\
\hline Energy Gap & $\mathrm{Eg} / \mathrm{eV}$ & Calculation: $h \mathrm{c} / \lambda^{\prime}$ ( $h$ is Planck's constant and $\mathrm{c}$ the speed of light) \\
\hline Electronaffinity & $\mathrm{EA} / e \mathrm{~V}$ & Calculation: PI-Eg \\
\hline
\end{tabular}

\subsection{Diagram Energy}

To estimate the potential ionization (IP) and electron affinity (EA) from the measured redox potentials, electrochemical potentials were correlated at the vacuum level. The standard hydrogen electrode (SHE) was used as the reference for the potential values $(\mathrm{E})$, which were then corrected using the vacuum level reference. The conversion from SHE to the vacuum reference was discussed originally by Trasatti (1983), who determined the energy corresponding to the standard hydrogen electrode (SHE) as $4.6 \pm 0.1 \mathrm{eV}$ at the zero-vacuum-level scale [42]. This is consistent with data in the literature, which point to an average of $4.6 \mathrm{eV}$, even though there may be deviations in the quoted values from author to author [43]. Thus, it was possible to calculate the oxidation potential onset relative to the vacuum level, since the oxidation potential onset $\mathrm{E}{ }_{\mathrm{ox}}$ in relation to the $\mathrm{Hg} / \mathrm{HgCl} / \mathrm{KCl}_{\text {(sat.) }}$ electrode $(4.7 \pm 0.1 \mathrm{eV}$ at the zero-vacuum level) was known from Eq. (2):

$$
\mathrm{E}_{\text {ox }}=\mathrm{E}_{\text {ox }}+\mathrm{E}_{\mathrm{Hg} / \mathrm{HgCl} / \mathrm{KCl} \text { (sat.) }} \approx \mathrm{E}_{\text {ox }}+\mathrm{E}_{\mathrm{vac}}+4.7
$$

Assuming $\mathrm{E}_{\mathrm{vac}}=0$, then IP $=e \mathrm{E}_{\mathrm{ox}}$ - where $e$ is the electron charge. This allowed the determination of the HOMO level in an energy diagram. Thus, the energy of the electronic transitions of the PAH/CuTsPc and PAH/NPS/PAH/CuTsPc films was estimated from the intersection of the two slopes drawn at maximum and background absorptions in the electronic spectra. The same was applied to the oxidation potentials, which were inferred from the intersection of the two slopes drawn at maximum and background currents in the cycle voltammogram, as depicted in Fig. 11.

In principle, the EA energy can be estimated by subtracting the energy gap [44] from the electronic spectra, according to Eq. (3):

$$
\mathrm{EA}=\mathrm{IP}-\mathrm{Eg}
$$



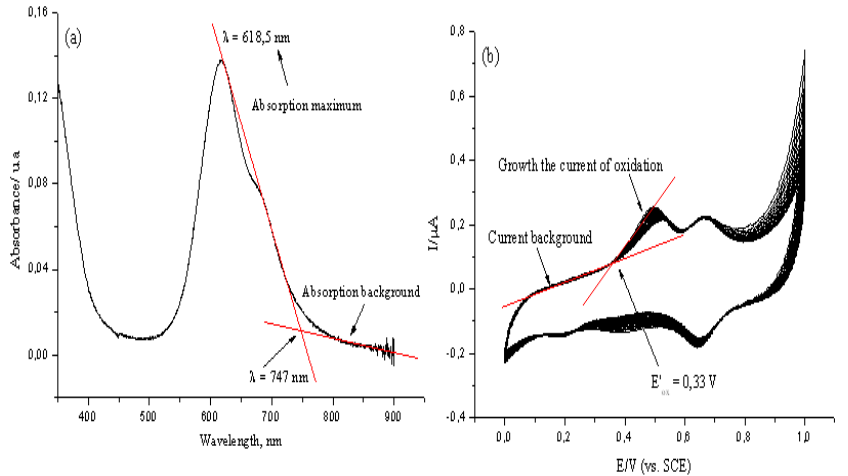

Figure11. Electronic spectra for (a) 10-bilayer PAH/CuTsPc and (b) cyclic voltammogram for 5-bilayer films.

Table 2 summarizes the means of obtaining each of the parameters used for constructing the energy diagrams of the electrodes.

Table 3 displays the results obtained for the potentials measured at the onset of oxidation measured at $50 \mathrm{mV} / \mathrm{s}$ (value changes at higher speed rates) for LbL films produced with sequence 1 and the absorption onset ( $\lambda$ ') that yielded the $\mathrm{Eg}$ values investigated in this work. The Eg should be taken as corresponding to the onset of the absorption curves, rather than to the peak maxima.

Table 3.The onset potentials for electrochemical oxidation $\left(E_{\text {ox }}{ }^{\prime}\right)$, ionization potentials (IP), absorption onsets ( $\left.\lambda^{\prime}\right)$, energy gap (Eg) and electron affinity (EA) values for $\mathrm{NPS} / \mathrm{CuTs} P \mathrm{C}$.

\begin{tabular}{cccc}
\hline Parameters & PAH/CuTsPc & PAH/Cashew/PAH/CuTsPc & PAH/Angico/PAH/CuTsPc \\
\hline E'ox (V) & 0.33 & 0.38 & 0.48 \\
PI (eV) & 5.03 & 5.08 & 5.18 \\
$\lambda^{\prime}(\mathrm{nm})$ & 747 & 747 & 747 \\
Eg (eV) & 1.661 & 1.661 & 1.654 \\
EA (eV) & 3.360 & 3.369 & 3.526 \\
\hline
\end{tabular}

The energy level diagrams were then calculated on the basis of the experimental data for $\mathrm{PAH} / \mathrm{CuTsPc}$, $\mathrm{PAH} / \mathrm{Cashew} / \mathrm{PAH} / \mathrm{CuTsPc}$ and $\mathrm{PAH} /$ Angico/PAH/CuTsPc films. Fig. 12 shows that the energy levels were similar for $\mathrm{PAH} / \mathrm{CuTsPc}$ and $\mathrm{PAH} / \mathrm{Cashew} / \mathrm{PAH} / \mathrm{CuTsPc}$, indicating similar characteristics of the two systems. A higher energy for the HOMO level revealed the need for higher potentials to oxidize CuTsPc/NPS molecules, this effect being more intense for the angico branco polysaccharide. As explained earlier, this can be attributed to large amounts of glucuronic acid, which is doubled in the cashew polysaccharide. This makes the redox process of the CuTsPc metal center overlap with that of the macrocycle. The carboxyl groups act by reducing the charge on the phthalocyanine ring, therefore requiring more energy for the reaction to occur.

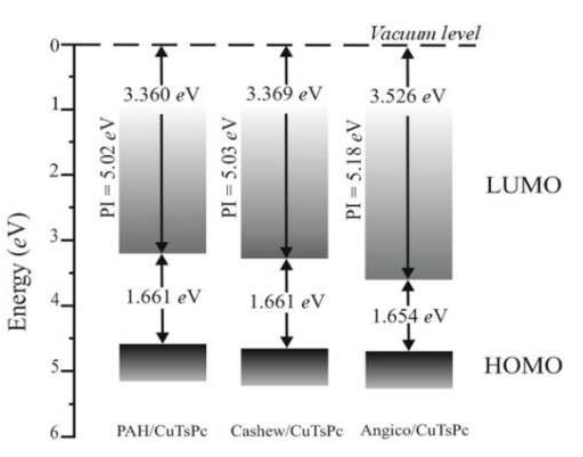

Figure12. Diagram of energy levels for PAH/CuTsPc, PAH/Cashew/PAH/CuTsPc and PAH/Angico/PAH/CuTsPc films.

\subsection{Dopamine Sensing}

The use of LbL films as modified electrodes for electrochemical sensing has been reported in the literature. The main advantages in using these films are the low detection limits and absence of residues [45,46]. A five-tetralayer of LbL films (sequence 1) was employed here as a modified electrode for DA detection. The DA oxidation through a two electron process [47,48] was evidenced by the increase in the peak current upon addition of DA in the electrochemical cell during the voltammetric measurements, as shown in Figure 13. DA was added with concentrations ranging from 25 to $90 \times 10^{-6} \mathrm{~mol} / \mathrm{L}$.

The detection limit [49] (DL) was estimated for $\mathrm{PAH} / \mathrm{CuTsPc}, \quad \mathrm{PAH} / \mathrm{Cashew} / \mathrm{PAH} / \mathrm{CuTsPc}$ and $\mathrm{PAH} /$ Angico/PAH/CuTsPc electrodes as show the Table 4, which is in good agreement with previously reported results $[20,39,48]$. For example, detection limits of $10^{-5} \mathrm{~mol} / \mathrm{L}$ have been reported by Siqueira et al., for LbL films of chitosan assembled with three types of sulfonated phthalocyanines containing iron (FeTsPc), nickel (NiTsPc), or copper (CuTsPc) [39].

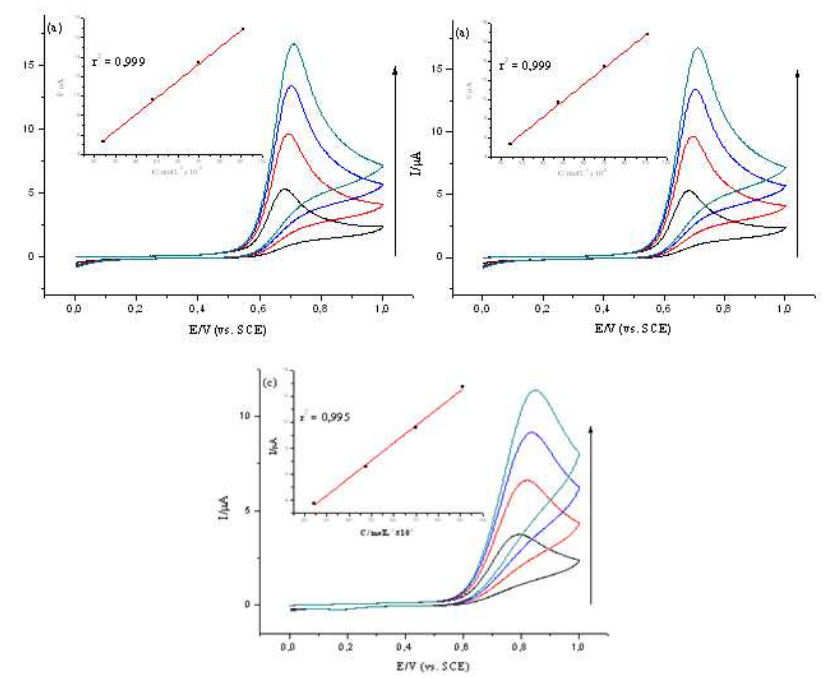

Figure13. Electrochemical response of an (a) $P A H / C u T s P c$, (b) $\mathrm{PAH} / \mathrm{Cashew/PAH/CuTs} \mathrm{Pc}$ and (c) PAH/Angico/PAH/CuTsPc electrodes in the presence of different amounts of DA in the electrolytic solution (0.05 mol/L $\mathrm{H}_{2} \mathrm{SO}_{4}$ ) at $50 \mathrm{mV} / \mathrm{s}$. Inset: Linear dependence of Ipal as a function of $D A$ concentration. 


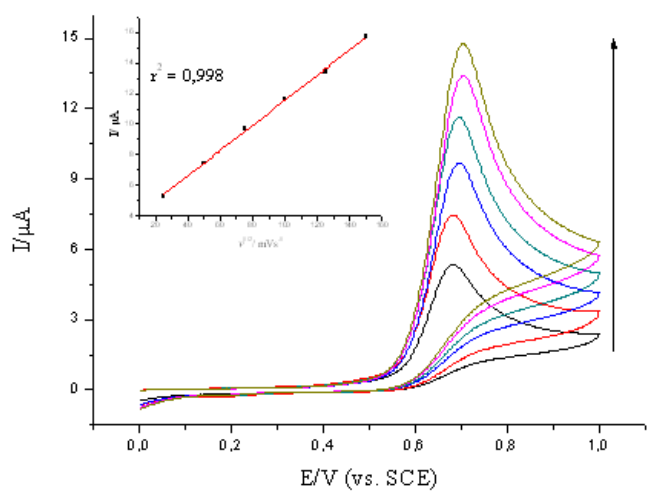

Figure14. Electrochemical response of a five-tetralayer $P A H / C u T s P c$ (sequence 1) in the presence of $90 \times 10^{-6} \mathrm{~mol} / \mathrm{L} \mathrm{DA}$ at different scan rates: (a) 10, (b) 30, (c) 50, (d) 75, (e) 100, and (f) $150 \mathrm{mV} / \mathrm{s}$. Inset: Linear dependence of the Ipal as a function of $v^{1 / 2}$.

The DA oxidation mechanism was investigated by varying the scan rate between 10 and $150 \mathrm{mV} / \mathrm{s}$, using the higher DA concentration of $90 \times 10^{-6} \mathrm{~mol} / \mathrm{L}$. The quadratic dependence of the peak current on the scan rate in Figure 14 points to a diffusional mechanism (observed for all films) [50]. The process is completely reversible, i.e., the peak current returned to the initial values if the film was cycled again in a DA-free electrolytic solution, after film washing. For comparison, DA detection was also carried out using a bare-ITO electrode under the same experimental conditions described above (not shown), and the results are summarized in Table 4. Were performed tests with ascorbic acid (AA) in presence of DA, which is a natural interferent for DA. Based on the results it is inferred that the electrodes were able to detect DA in the presence of AA, showing only one oxidation process in $0.70 \mathrm{~V}$. It can be seen that as far as the DA detection is concerned, electrodes bearing a bi/tetralayer architecture are advantageous due to the lower limit of detection exhibited by these systems, highlighting the film $\mathrm{PAH} / \mathrm{Cashew} / \mathrm{PAH} / \mathrm{CuTsPc}$.

Table4. Equation calibration, correlation coefficient $\left(r^{2}\right)$, detection limit (DL), Ipa, and oxidation potential for different electrodes subjected to DA detection $^{a}$.

\begin{tabular}{cccc}
\hline Electrodes & Equation calibration & $\mathbf{r}^{2}$ & DL $(\boldsymbol{\mu m o l} / \mathbf{L})$ \\
\hline PAH/FtTsCu & $\mathrm{I}_{\mathrm{pa} 1}(\mu \mathrm{A})=1.259+1.724 \times 10^{5} \mathrm{C}^{b}$ & 0.999 & 0.227 \\
$\mathrm{PAH} / \mathrm{Cashew} / \mathrm{PAH} / \mathrm{FtTsCu}$ & $\mathrm{I}_{\mathrm{pal}}(\mu \mathrm{A})=0.756+2.002 \times 10^{5} \mathrm{C}^{b}$ & 0.998 & 0.195 \\
$\mathrm{PAH} /$ Angico/PAH/FtTsCu & $\mathrm{I}_{\mathrm{pal}}(\mu \mathrm{A})=0.199+1.377 \times 10^{5} \mathrm{C}^{b}$ & 0.995 & 0.387 \\
\hline
\end{tabular}

${ }^{a}$ All of the electrodes presented reversibility after washing.

${ }^{\mathrm{b}}$ The concentration of DA in $\mathrm{mol} / \mathrm{L}$.

\section{Conclusion}

Supramolecular structures containing natural polyelectrolyte gums and copper tetrasulfonated phthalocyanine were assembled using the $\mathrm{LbL}$ technique in two tetralayer architectures. The LbL film assembled in sequence (1) exhibited the best electrochemical response, and the films displayed good electrochemical stability and reversibility. The latter allowed the estimation of the HOMO energy. Based upon cyclic voltammetry and reports from the literature, we inferred that charge transfer within the multilayered architecture probably occurred via electron-hopping.

The use of mathematical deconvolution allowed the separation of the voltammetric peaks and, consequently, the quantification of the anodic and cathodic charges of each redox process. Additionally, the proposed method can be applied to control charge density of thin films. Based on electrochemical and electronic absorption experiments, IP, $\mathrm{Eg}$ and EA were estimated, which were similar for the two systems studied with the natural polysaccharides.

The tetralayer films containing Angico did not show advantages in terms of dopamine detection, in comparison with Cashew films that reached the better and lower detection limits (on the order of $10^{-5} \mathrm{~mol} / \mathrm{L}$ ).
The possibility of assembling natural gums with semiconductor organic molecules opens up new prospects for using these natural biodegradable materials in technological applications.

\section{References}

[1] Gao, W. T.; Zhang, S. F.; Yang, J. Z.; \& Huang, L. Metal phthalocyanine catalyzed oxidation of 4-nitrotoluene-2-sulfonic acid to 4,4'-dinitrostilbene-2, 2'-disulfonic acid. Dyes Pigm. 44 155-159(2000).

[2] Albertini, V. R.; Generosi, A.; Paci, B.; Perfetti, P.; Rossi, G.; Capobianchi, A.; Paoletti, A. M.; Caminiti, R. Time-resolved energy dispersive $\mathrm{x}$-ray reflectometry measurements on ruthenium phthalocianine gas sensing films. Appl. PhysLett. 82 3868-3871(2003).

[3] Leznoff, C. C., Lever, A. B. P. Phthalocyanines: Properties and Applications. Cambridge: WileyVCH. 1996.

[4] Chen, Y.; O'Flaherty, S. M.; Hanack, M.; Blau, W. J. New axially aryloxy substituted gallium phthalocyanines for nonlinear optics. J. Mater. Chem. 13 2405-2408(2003).

[5] Tsujioka, T.; Hamada, Y.; Shibata, K.; Taniguchi, A.; Fuyuki, T. Nanodestructive readout of photochromic optical memory using photocurrent detection. Appl. Phys. Lett. 78 2282-2285(2011). 
[6] Brito, A. C. F.; Silva, D. A.; Paula, R. C. M.; Feitosa, J. P. A. Sterculiastriata exudate polysaccharide: characterization, rheological properties and comparison with Sterculiaurens (karaya) polysaccharide. Polym. Int. 53 1025-1032(2004).

[7] Brito, A. C. F.; Sierakowski, M. R.; Reicher, F.; Feitosa, J. P. A.; Paula, R. C. M. Dynamic rheological study of Sterculiastriata and karaya polysaccharides in aqueous solution. Food Hidrocolloids. 19 861-867(2005).

[8] Silva, D. A.; Brito, A. C. F.; Paula, R. C. M.; Feitosa, J. P. A.; Paula, H. C. B. Effect of mono and divalent salts on gelation of native, $\mathrm{Na}$ and deacetylatedSterculiastriata and Sterculiaurens polysaccharide gels. Carbohydrate Polymers. 54 229-236(2003).

[9] Aquino, A. R. L.; Rossetti, A. G. Influência do tipo de ramo sobre o crescimento e produção do cajueiro anão precoce de copa substituída. Rev. Bras. Fructi. 24 756-758(2002).

[10] Verbeken, D.; Dierckx, S.; Dewettinck, K. Exudate gums: occurrence, production, and applications. Appl. Microbiol. Biotechnol. 63 10-21(2003).

[11] Yebeyen, D.; Lemenih, M.; Feleke, S. Characteristics and quality of gum arabic from naturally grown Acacia senegal (Linne) Willd. trees in the Central Rift Valley of Ethiopia. Food Hydrocolloids. 23 175-180(2009).

[12] Gyedu-Akoto, E.; Oduro, I.; Amoah, F. M.; Oldham, J. H.; Ellis, W. O.; Opoku-Ameyaw, K.; Asante, F.; Bediako, S. Quality estimation of cashew gum in the production of chocolate pebbles. African J. Food Sci. Technol. 2 16-20(2008).

[13] Mothé, C.G.; Correia, D.Z.; Carestiao, T. Potencialidades do Cajueiro: caracterização tecnológica e aplicação. Rio de Janeiro: Publit Soluções Editoriais Ltda. 2006.

[14] Schirato, G. V.; Monteiro, F. M. F.; Silva, F. O.; Lima Filho, J. L.; Leão, A. M. A. C.; Porto, A. L. F. O polissacarídeo do Anacardium occidentale L. na fase inflamatória do processo cicatricial de lesões cutâneas. Ciência Rural. 36 149-154(2006).

[15] Mothé, C. G.; Rao, M. A. Rheological behavior of aqueous dispersions of cashew gum and gum arabic: effect of concentration and blending. Food Hydrocolloids. 13 501-506(1999).

[16] Gyedu-Akoto, E.; Oduro, I.; Amoah, F. M.; Oldham, J. H.; Ellis, W.O.; Opoku-Ameyaw, K. Rheological properties of aqueous cashew tree gum solutions. Sci. Res. Essay. 2 458-461(2007).

[17] Toma, H.E. O mundo nanométrico: a dimensão do novo século.São Paulo: Oficina de textos. 2004.

[18] Irvine, J. T. S.; Eggins, B. R. The cyclic voltammetry of some sulphonated transition metal phthalocyanines in dimethylsulphoxide and in water. J. Electroanal. Chem. 271 161-172(1989)

[19] Nevin, W. A.; Liu, W.; Melnik, M.; Lever, A. B. P. Spectro-electrochemistry of cobalt and iron tetrasulphonated phthalocyanines. J. Electroanal. Chem. 213 217-234(1986).

[20] Zucolotto, V.; Ferreira, M.; Cordeiro, M.R.; Constantino, C. J.
L.; Moreira, W. C.; Oliveira Jr, O. N. Nanoscale manipulation of polyaniline and phthalocyanines for sensing applications. Sens. Actuators B. 113 809-815(2006).

[21] Paterno, L. G.; Mattoso, L.H.C.; Oliveira Jr, O. N. Filmes poliméricos ultrafinos produzidos pela técnica de automontagem: preparação, propriedades e aplicações. Quim. Nova. 24 228-235(2001).

[22] Zucolotto, V.; Ferreira, M.; Cordeiro, M. R.; Constantino, C. J. L.; Balogh, D. T.; Zanatta, A. R.; Moreira, W. C.; Oliveira $\mathrm{Jr}$, O. N. Unusual interactions binding iron tetrasulfonated phthalocyanine and poly(allylamine hydrochloride) in layer-by-layer films. J. Phys. Chem. B. 107 3733-3737(2003).

[23] Schönhoff, M. Self-assembled polyelectrolyte multilayers. Curr. Opin. Colloid Interface Sci. 8 86-95(2003).

[24] Frost, R. L.; Erickson, R. L.; Weier, M. L.; Carmody, O. Raman and infrared spectroscopy of selected vanadates.Spectrochim. Acta, Part A. 61 829-834(2005).

[25] Frost, R. L. An infrared and Raman spectroscopic study of natural zinc phosphates O. Spectrochim. Acta, Part A. 60 1439-1445(2004).

[26] Micaroni, L.; Nart, F.C.; Hummelgen, I. A. Considerations about the electrochemical estimation of the ionization potential of conducting polymers. J. Solid State Electrochem. $755-59(2002)$.

[27] Garcia, J. R.; Peres, L. O.; Fernandes, M. R.; Gruber, J.; Nart, F. C. One-step electrochemical synthesis of pure poly(2,5-dicyano- $p$-phenylenevinylene) films. J. Solid State Electrochem. 8 122-126(2004).

[28] Eckhardt, H.; Shacklette, L. W.; Jen, K. Y.; Elsenbaumer, R. L. The electronic and electrochemical properties of poly(phenylenevinylenes) and poly(thienylenevinylenes): An experimental and theoretical study. J. Chem. Phys. 91 1303-1316(1989).

[29] Janietz, S.; Bradley, D. D. D.; Grell, M.; Giebeler, C.; Inbasekaran, M.; Woo, E. P. Electrochemical determination of the ionization potential and electron affinity of poly(9,9-dioctylfluorene). Appl. Phys. Lett. 73 2453-2456(1998).

[30] Roman, L. S.; Hümmelgen, I. A.; Nart, F. C.; Peres, L. O.; Sá, E. L. Determination of electroaffinity an ionization potential of conjugated polymers via Fowler - Nordheim tunneling measurements: Theorical formulation and application to poly(p-phenylenevinylene). J. Chem. Phys. 105 10614-10621(1996).

[31] Spaepen, H.; Campbell, I. H.; Smith, D. L. Physics of organic devices. In F. Ehrenreich (Ed.), Solid state physics advances in research and applications. London: Academic Press. 2001

[32] Costa, S. M. O.; Rodrigues, J. P. A.; De Paula, R. C. M. Monitorização do processo de purificação de gomas naturais: goma do cajueiro. Rev. Bras. Eng. Agríc. Ambient. 2 49-54(1996).

[33] H. Wang, D. Loganathan, R. J. Linhardt. Determination of the $\mathrm{pKa}$ of glucuronic acid and the carboxy groups of heparin by 13C-nuclear-magnetic resonance spectroscopy. Biochem. J. 278 689-695(1991). 
[34] Bard, A. J., Parsons, R., and Jordan, J. Standard Potentials in Aqueous Solutions, Marcel Dekker, New York. 1985.

[35] Crespilho, F.N.; Zucolotto, V.; SiqueiraJr, J.R.; Carvalho, A. J. F.; Nart, F.C.; Oliveira Jr, O. N. Using electrochemical data to obtain energy diagrams for layer-by-layer films from metallic phthalocyanines. Int. J. Electrochem. Sci. 1 151-159(2006).

[36] Motulsky, H.; J.Analysing data with graphpad prism. San Diego: Graphpad Software. 1999.

[37] Agostinho, S. M. L.; Villamil, R. F. V.; Agostinho Neto, A.; Aranha, E. O eletrólito de suporte e suas múltiplas funções em processos de eletrodo. Quim. Nova. 27 813-817(2004).

[38] Crespilho, F. N.; Zucolotto, V.; Oliveira Jr, O. N.; Nart, F. C. Electrochemistry of layer-by-layer films: a review. Int. J. Electrochem. Sci. 1 194-214(2006).

[39] SiqueiraJr, J.; Gasparotto, L. H. S.; Crespilho, F. N.; Carvalho, A. J. F.; Zucolotto, V.; Oliveira Jr, O. N. Physicochemical properties and sensing ability of metallophthalocyanines/chitosan nanocomposites. J. Phy. Chem. B. 110 22690-22694(2006).

[40] S., Trasatti. Structuring of the solvent at metal/solution interfaces and components of the electrode potential.Electroanal. Chem. 150 1-15(1983).

[41] Xie, Q.; Kuwabata, S.; Yoneyama, H. EQCM studies on polypyrrole in aqueous solutions. J. Electroanal. Chem. 420 219-272(1997).

[42] Bredas, J. L. Electronic structure of highly conducting polymers. In: T.A. Skotheim (Ed.), Handbook of conducting
polymers.New York: Dekker. 1986

[43] Fermin, D. J.; Teuel, H.; Scharaifker, B. R. Changes in the population of neutral species and charge carriers during electrochemical oxidation of polypyrrole. J. Electroanal. Chem. 401 207-214(1996).

[44] Stockert, D.; Kessel, R.; Schultze, J. W. Absorption, photocurrent and photoelectron spectra of heterocyclic polymers. Synth. Met. 41 1295-1300(1991).

[45] Lawrence, N. S.; Beckett, E. L.; Davis, J.; Compton, R. G. Advances in the voltammetric analysis of small biologically relevant compounds. Anal. Biochem. 303 1-16(2002).

[46] Skoog, D. A.; Holler, F. J. Princípios de análise instrumental, 5th ed.; Bookman: 2002.

[47] Oni, J.; Nyokong, T. Simultaneous voltammetric determination of dopamine and serotonin on carbon paste electrodes modified with iron(II) phthalocyanine complexes. Anal. Chim. Acta 434 9-21(2001).

[48] Ferreira, M.; Dinelli, L. R.; Wohnrath, K.; Batista, A. A. A.; Oliveira, O. N., Jr. Langmuir-Blodgett films from polyaniline/ruthenium complexes as modified electrodes for detection of dopamine. Thin Solid Films. 446 301-306(2004)

[49] Lanças, F. M. Validação de métodos cromatográficos de análise; Rima: São Carlos, Brazil. 2004.

[50] Brett, C. M. A.; Brett, A. M. O. Electroquímica: princípios, métodos e aplicações, Vol. 1; Almedina: Coimbra, Portugal. 1996. 